\author{
Gianni Allegro* - Pier Mauro Giachino**
}

\title{
Hiletus walterrossii new species from Sierra Leone, Africa (Coleoptera Carabidae, Hiletini)
}

\begin{abstract}
Riassunto: Hiletus walterrossii nuova specie della Sierra Leone, Africa.
Viene descritto Hiletus walterrossii nuova specie della Sierra Leone, Africa. Soltanto sei specie appartenenti al genere Hiletus erano note fino ad oggi, tutte distribuite nella fascia tropicale africana. La nuova specie appartiene al gruppo di H. alluaudi sensu Erwin \& Stork (1985). Viene fornita una chiave di identificazione per le specie appartenenti a questo gruppo e i caratteri utili a distinguere la nuova specie vengono discussi e illustrati.
\end{abstract}

\begin{abstract}
Hiletus walterrossii new species is described from Sierra Leone, Africa. Only six Hiletus species were known so far, all confined to tropical Africa. The new species belongs to the alluaudi group sensu Erwin \& Stork (1985). An identification key to this species group is provided and the features useful to distinguish species are discussed and illustrated.
\end{abstract}

Key words: Coleoptera, Carabidae, Hiletini, new species, Sierra Leone, Africa, identification key.

\section{INTRODUCTION}

Hiletini (recently regarded by Lorenz (2005) as the subfamily Hiletinae) are an ancient tribe of Carabidae closely related to PseudomorphiniCnemacanthini-Scaritini (Erwin \& Stork, 1985). Their distribution is pantropical, with 21 species described so far (Lorenz, 2005; Assmann et al., 2011). Jeannel (1937) first tried a systematic arrangement of Hiletini, including the Asian as well as the African species in the genus Hiletus Schiödte, 1847 (attributing the species from Asia to the subgenus Parahiletus Jeannel, 1937 and subdividing the species from Africa into the subgenera Hiletus s. str. and Eucamaragnathus Jeannel, 1937) and the unique South-American species known at that time in the genus Neohiletus Jeannel, 1937. This view-point was accepted by Négre (1966), whilst Erwin \& Stork (1985) considered Parahiletus and Neohiletus as synonyms of Eucamaragnathus, regarded as a genus, mainly on account of the common character of the mesal edge of mandibles markedly serrate on its whole length (in Hiletus the edge is markedly serrate only in the basal half), despite some striking differential features of male genitalia like the dextral or sinistral position of the ostium in species with different biogeographical origin. In order to retain these differences, the same Authors recognized within both genera the presence of 'species groups' including species which they consider as probably close relatives and which are generally distributed in common geographical areas. The same systematic approach was adopted by Lorenz (2005), Assmann et al. (2011) and Aston (2015). Although an updated revision based on more abundant material is probably needed, a discussion of the systematic arrangement of Hiletini is beyond the scope of this article, which only concerns the description of a new entity from Western Africa.

All Hiletini (or Hiletinae) species share a rather uniform external morphology of the adults, showing some peculiar features such as the geniculate antennae (like Dryptinae, Promecognathinae and Siagoninae) with the first antennomere approximately as long as the next five, the mandibles concave beneath and each with eight to nine teeth, the tarsi slender and tapered distally, as well as a rather primitive morphology of the aedeagus. The larval stages of Hiletini are currently unknown.

Hiletini are recorded from Africa, Madagascar, South America and Southeast Asia. They usually live

\footnotetext{
*Gianni Allegro, CREA Consiglio per la Ricerca in Agricoltura e l'Analisi dell'Economia Agraria. Centro di Ricerche Foreste e Legno, Strada Frassineto 35, 15033 Casale Monferrato (AL), Italy.

E-mail: gianni.allegro@crea.gov.it

** Pier Mauro Giachino, Settore Fitosanitario Regionale, Environment Park, Palazzina A2, Via Livorno 60, 10144 Torino, Italy. E-mail: piermauro.giachino@regione.piemonte.it
} 
in tropical and subtropical climates with a mean annual temperature above $21^{\circ} \mathrm{C}$ and mean annual rainfall above $200 \mathrm{~cm}$. The preferred habitats are broadleaf evergreen or deciduous forests, or grassland savannahs with scattered or gallery trees. Due to the morphology of the mouthparts, the adults probably only take liquid food (Erwin \& Stork, 1985).

This tribe is generally poorly known mainly because of the paucity of material in collections, with only few species adequately represented. Consequently, the taxonomic literature concerning Hiletini is poor too, with only a few articles devoted to the revision and the systematic arrangement of the tribe (Jeannel, 1937; Nègre, 1966; Erwin \& Stork, 1985).

The genus Hiletus (type species: Hiletus versutus Schiödte, 1847) currently includes six species restricted to tropical Africa. They are listed below with their respective distribution:

\section{H. alluaudi group}

H. alluaudi Jeannel, 1937

Ivory Coast, Ghana

H. jeanneli Nègre, 1966 Sierra Leone

H. katanganus Basilewsky, 1948

Zaire, Republic of Malawi

H. nimba Erwin \& Stork, 1985

Guinea

H. versutus group

H. versutus Schiödte, 1847

=H. guerini Bocandé, 1849

H. fossulatus Jeannel, 1937

Western Africa

=H. fissipennis sensu Kolbe, 1897

The study of the material collected in Sierra Leone by Walter Rossi and deposited in collection Allegro and in collection Giachino brought to light a new Hiletus species which is described and illustrated herein. Since the new species proved to belong to the alluaudi species group, the key to the species of this group given by Erwin \& Stork (1985) is updated and the features useful to distinguish species are discussed and illustrated.

\section{MATERIALS AND MSETHODS}

The specimens of the new species are deposited in the following Museums and private Collections: MNHNP: Muséum National d'Histoire Naturelle, Paris, France; CAl: G. Allegro Collection
(Moncalvo, Asti, Italy), CGi: P.M. Giachino Collection (Torino, Italy).

The abbreviations used for the type material are: TS type series; HT holotype; PT, PTT paratype(s). The type locality is quoted in the original label form.

Digital images were taken with a Leica DFC295 camera mounted on a Leica M205 C Stereomicroscope, using Leica Application System V4.0 software.

\section{Hiletus walterrossii sp. $\mathrm{n}$.}

TyPe LOCALity: Sierra Leone, Western Area, Banga Farm near Sussex.

TYPE SERIES. HT $\partial$, Sierra Leone, Western Area, Banga Farm near Sussex, 16.XI.2015, W. Rossi legit (CGi). PTT: $1 \delta^{\lambda} 2$ 우, same data as the holotype (MNHNP, CAl).

DiagnOSIS. Adults 9.17-9.65 mm long, shiny black without metallic lustre; legs black; antennae piceous with antennomeres 5-11 paler, the scape as long as the next five articles (Fig. 1); occlusal margin of mandibles dentate with the apical teeth larger and blunter (Fig. 2). It is easily distinguished from the species of the versutus group by the smaller size, the palpi not securiform and the lack of metallic lustre; within the alluaudi group, it is distinguished from $H$. alluaudi and $H$. jeanneli by the presence of foveate setigerous punctures on the third elytral stria (punctiform in H. alluaudi and H. jeanneli), from $H$. katanganus by the presence of two setigerous punctures on the third elytral stria (three in H. katanganus), from $H$. nimba by the smaller size (overall length of $H$. nimba HT from labrum to apex of elytra: $10.26 \mathrm{~mm}$ ), the less transverse pronotum, by the narrower margin of pronotum at the fore-angles (Fig. 3) and by the coarser punctures (three times wider than stria) in the four inner elytral striae (at most two times wider than stria in H. nimba) (Fig. 4).

DESCRIPTION. Habitus moderately short and broad, compactly structured (Fig. 1). Overall length of the HT $\widehat{\delta}$ (from labrum to apex of elytra) $9.46 \mathrm{~mm}$ (PT $\hat{o} 9.17$, PTT 우우 9.21-9.65 mm). Dorsal surface black with slight iridescence, shiny. Microsculpture very superficial, hardly distinct only on elytra. Antennal scape piceous, flagellum paler with apical antennomeres rufous; legs piceous with tarsi brownish; mouthparts brown. Metathoracic wings fully developed.

Head large, slightly restricted behind eyes with a coarsely punctate transverse sulcus. Eyes large and 
convex; frontal furrows long and deeply impressed, slightly divergent anteriorly and nearly parallel in the basal half. Clypeus asetose, concave at sides. Labrum transverse with a single seta at each anterior corner, not or shallowly concave, faintly and transversally wrinkled at middle. Two supraorbital setae. Frons between the frontal impressions smooth and shiny. Mandibles large and concave beneath, each bearing eight to nine robust triangular teeth at the occlusal margin, with the last two to three larger and blunter (Fig. 2). Apical labial palpomere fusiform. Submentum with four long setae extending across the concav-

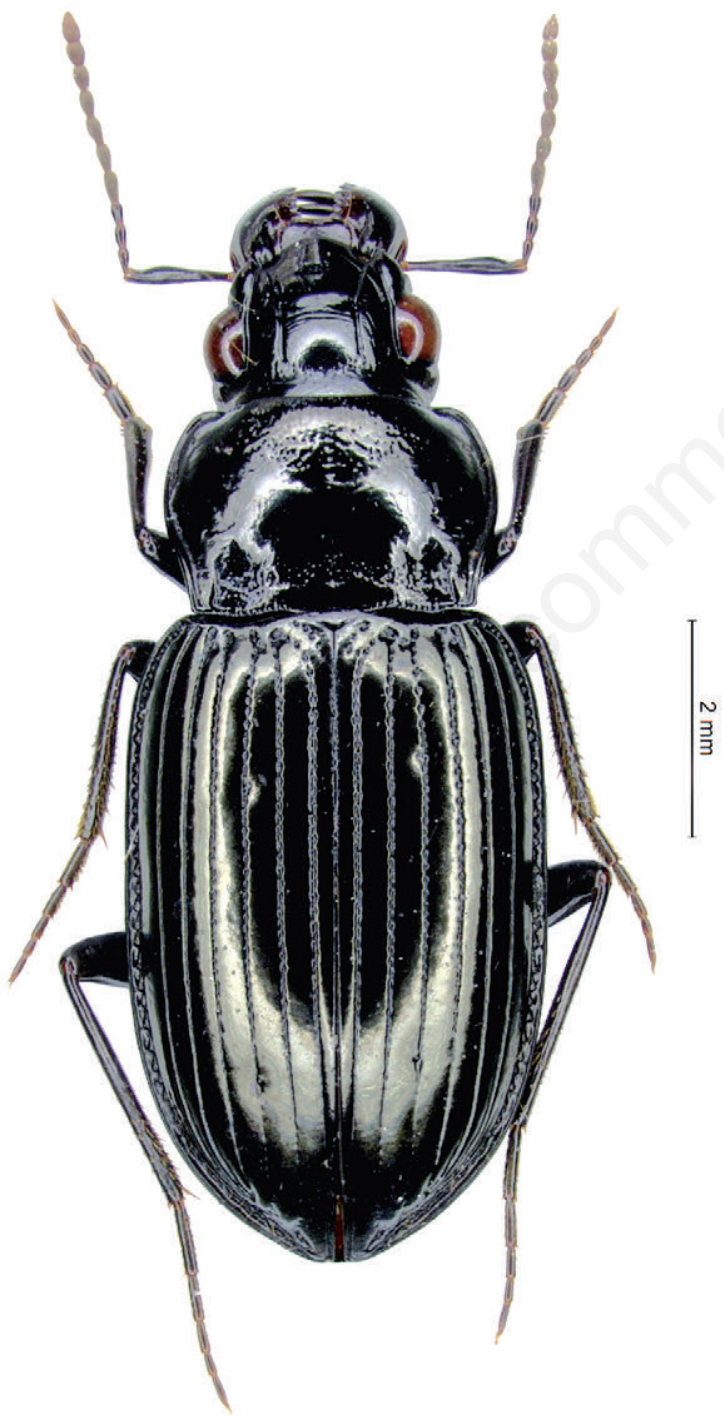

Fig. 1. Habitus of Hiletus walterrossii n. sp. HT $\overbrace{}^{\lambda}$.

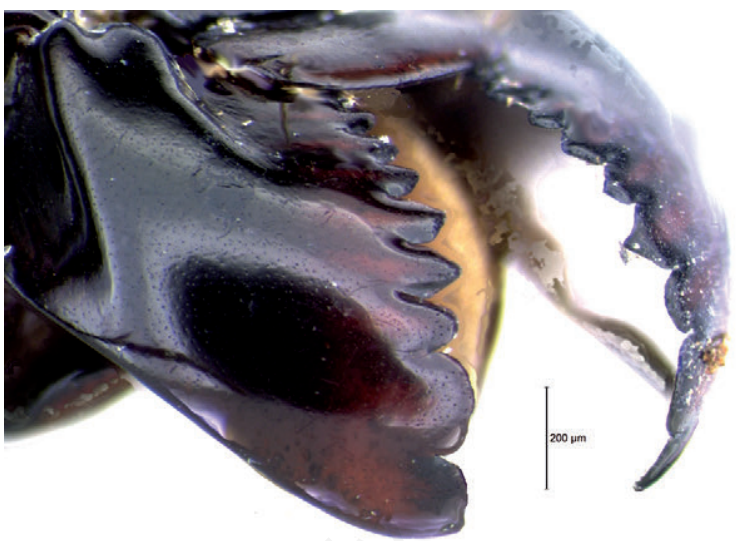

Fig. 2. Mouth parts of Hiletus walterrossii n. sp. HT $\delta$ in right dorsolateral view, with distal portion of the right mandible on left side, and toothed cutting edge of left mandible on right side of the digital image.

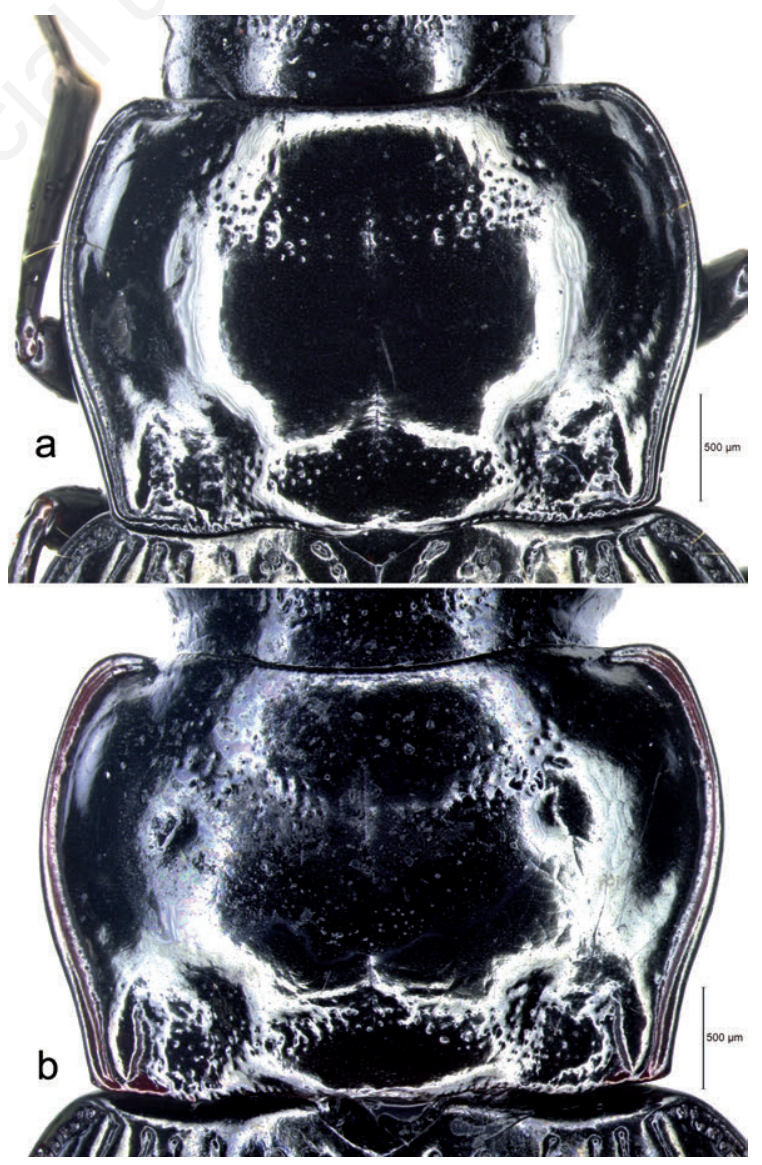

Fig. 3. Pronotum of Hiletus walterrossii n. sp. PT $q$ (a) and of Hiletus nimba $\mathrm{HT}+$ (b). 
ity in the mentum. Antennae geniculate, with scape approximately as long as the next five antennomeres.

Pronotum transverse (width/length: 1.51), broadly cordiform, wider at base than at anterior margin and with maximum width just before middle (Fig. 3a). Microsculpture absent over the whole surface, disc smooth and shiny. Two basal impressions on each side; the inner one wide and coarsely punctate, the external linear and markedly impressed. Mid longitudinal line distinctly impressed between the submarginal sulci, which are coarsely punctate. Sides slightly sinuate towards basal angles; lateral bead narrower in the anterior half and near fore-angles, which are scarcely produced; lateral depression smooth and narrower in the anterior half. Anterior and posterior margins only beaded close to angles; base sinuous, medially convex. Hind angles marked and slightly obtuse, without lat-
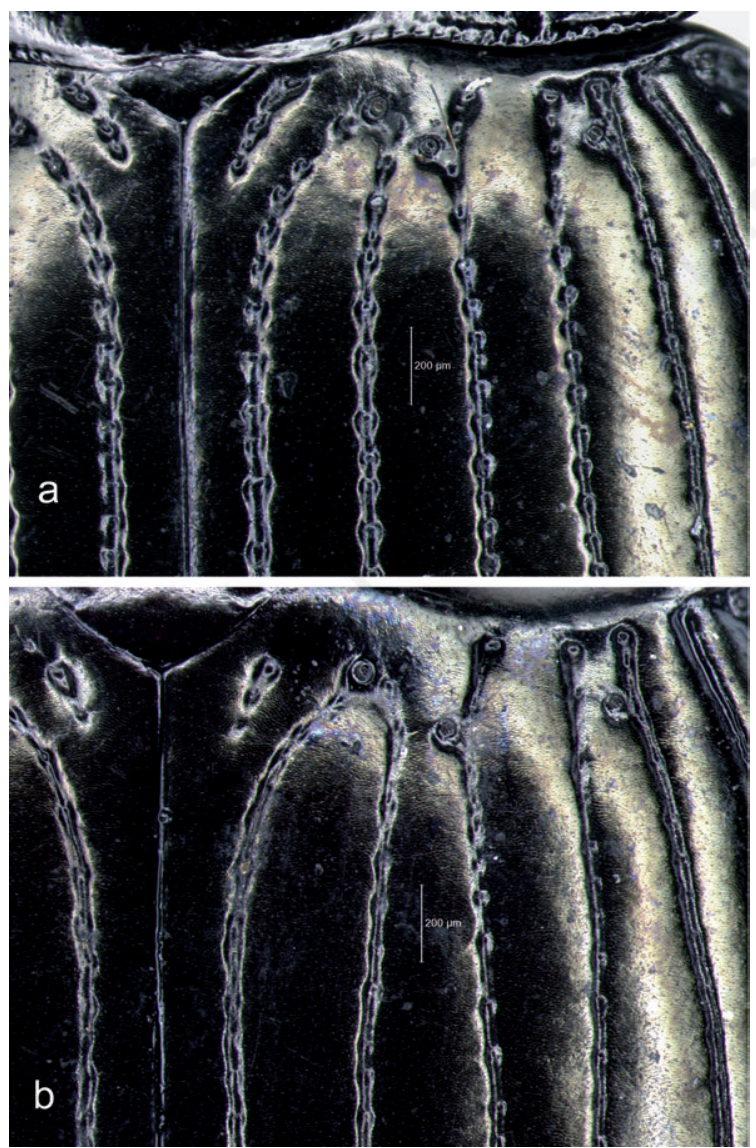

Fig. 4. Basal part of elytra of Hiletus walterrossii n. sp. PT ㅇ (a) and of Hiletus nimba $\mathrm{HT} q$ (b). ero-basal seta. One lateral seta on each side at about $2 / 3$ from base. Prosternal process glabrous, rounded and distinctly margined.

Elytra broad basally, nearly parallel sided (length/width: 1.61), convex. Microsculpture very superficial, transverse, indistinct. Shoulders rounded, without denticle. A short scutellar stria present between suture and stria 1 . The basal margin reaches the $5^{\text {th }}$ stria. Three basal pores, the first at the junction of striae 1 and 2, the second adjoined to the base of stria 3 and the third adjoined to the base of stria 5 (Fig. 4a). Sides nearly linear and parallel, not sinuate near apex; lateral bead narrow with lateral depression punctate over the whole length. Each elytron with two setigerous punctures in foveate depressions on the third stria, the $1^{\text {st }}$ at basal $4^{\text {th }}$, the second at the apical $4^{\text {th }}$. Striae 1-4 deeply impressed, in the basal half with coarse and dense punctures widely exceeding the width of striae (about three times wider than striae) (Fig. 4); striae 56 well impressed but more faintly punctate; stria 7 effaced except at apex. Intervals hardly convex.

Metepisterna distinctly longer than wide, from superficially rugulose to nearly smooth. Abdominal sterna IV-VII glabrous except for the pair of central setae.

Legs slender. Tibiae straight. Male profemora with a small blunt ventral denticle. Metatrochanters short and ovate. Tarsi slender and tapered distally; male protarsomeres slightly dilated.

Median lobe of aedeagus (Fig. 5a) curved in lateral view except in the basal part, wider in the median portion and bent downward at the rounded apex. The endophallus is formed by a complex apparatus with trichia and small spines. Left paramere broad medially, multisetose in the apical half; the right one curved and narrow, elongate, setose in the apical half and more densely at apex (Fig. 5b). Subgonocoxites densely multisetose in the distal half, glabrous at base; gonocoxites small and short, with robust setae in the basal half and rounded at tip; two groups of three setae, the first ones longer and thicker, the second shorter and thinner, subapically inserted (Fig. 6).

Etymology. This species is dedicated to its collector, Walter Rossi, a world renowned specialist in entomoparasitic fungi, as a token of our esteem and as a sign of gratitude for the gift to the authors of the specimens of the new species.

DisTRIBUTION AND HABITAT. At present $H$. walterrossii 
sp. $\mathrm{n}$. is only recorded from the type locality of Banga Farm near Sussex (Sierra Leone, Western Africa).

Comparative notes. Hiletus walterrossii n. sp. definitely belongs to the alluaudi species group sensu Erwin \& Stork (1985), because of the following characters: terminal labial palpomere not securiform, the size medium or small $(<12.5 \mathrm{~mm})$ and the body surface black or piceous without metallic lustre. Inside the alluaudi species group it is easily distinguished from $H$. alluaudi and $H$. jeanneli by the presence of foveae on the third elytral stria, from $H$. katanganus by the presence of two discal setae. As far as the external morphology is concerned, the most similar species is $H$. nimba, which is recorded from Guinea, Nimba Mountains, at 1,600 m elevation. This is the highest elevation recorded for the whole tribe. This

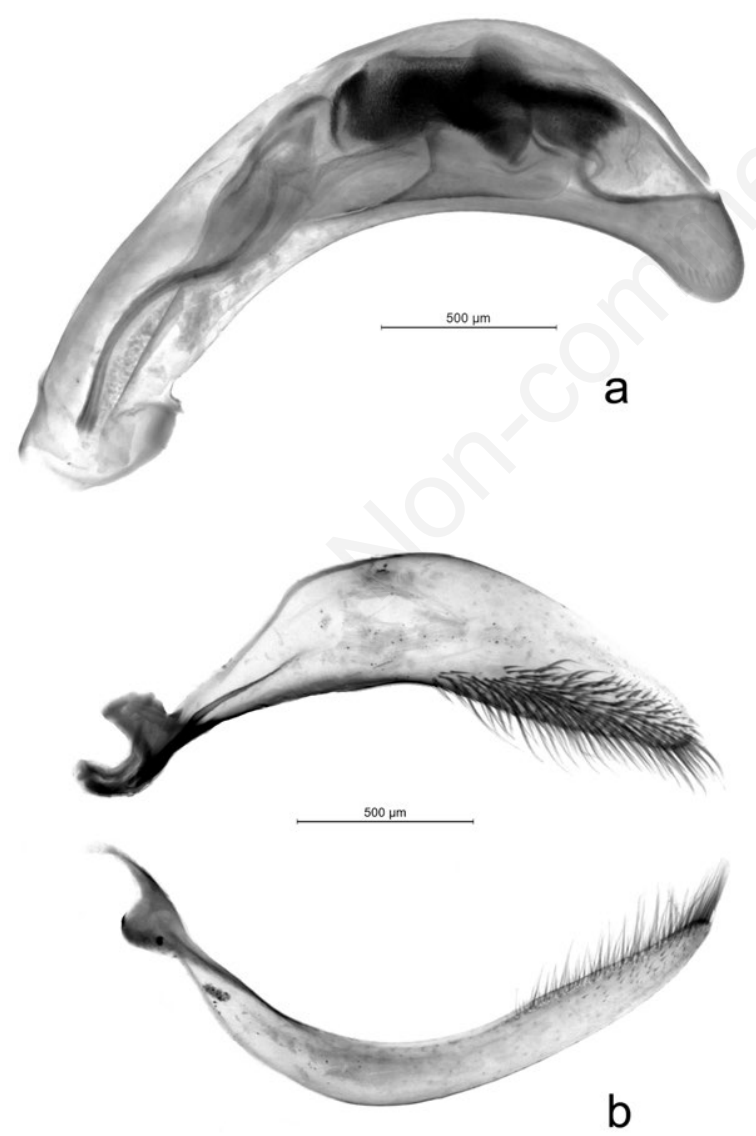

Fig. 5. Aedeagus with median lobe (a) and parameres (b) of Hiletus walterrossii $\mathrm{n}$. $\mathrm{sp}$. HT $\widehat{\delta}$. species description was based on a unique female specimen, deposited at MNHNP, thus a comparison of the aedeagus is impossible.

Regardless, the examination of the female HT of $H$. nimba and its comparison with the type specimens of $H$. walterrossii n. sp. (in particular with the female PTT) convinced us of the validity of this new species due to the following differences in the external morphology: the $H$. walterrossii n. sp. specimens range from 9.17 to $9.65 \mathrm{~mm}$ in overall length from labrum to apex of elytra, significantly shorter than H. nimba HT (10.26 mm); in H. walterrossii n.sp. the pronotum is less transverse (W/L: 1.51) and is wider at base than at anterior margin, in $H$. nimba the pronotum is more transverse (W/L: 1.55) and is as wide at the base as at the anterior margin; in $\mathrm{H}$. walterrossii $\mathrm{n}$. sp. the lateral bead and the lateral depres-

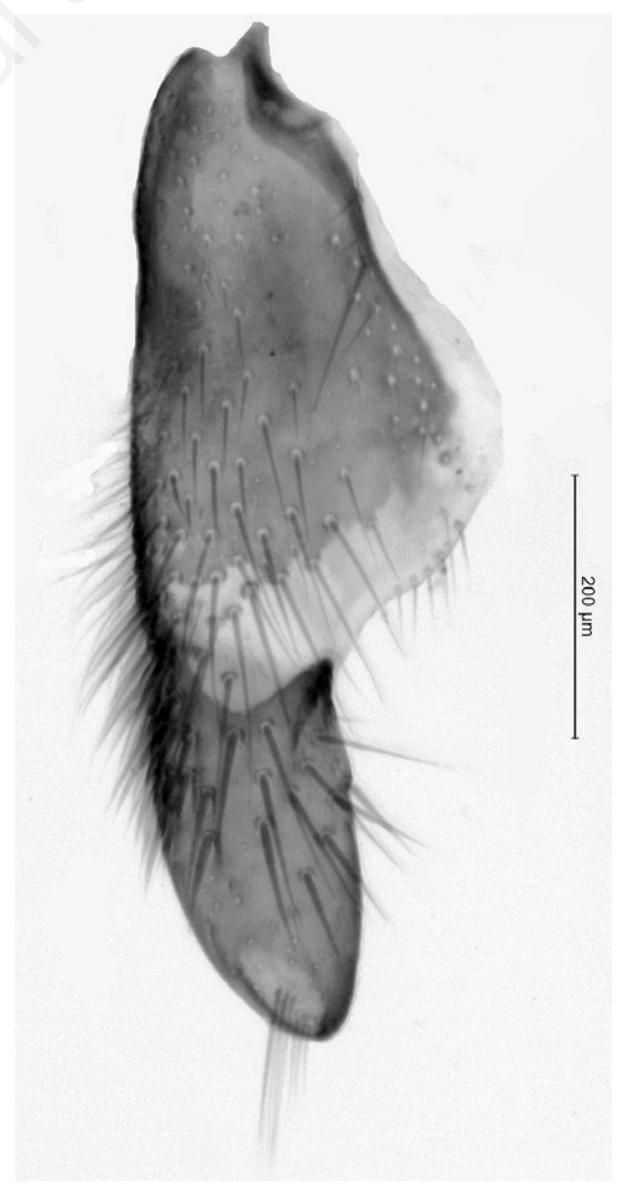

Fig. 6. Left gonocoxites of Hiletus walterrossii n. sp. PT ${ }_{+}$. 
sion of the pronotum near the fore-angles are distinctly narrower than at the basal half (Fig. 3a), in $H$. nimba the lateral bead and the lateral depression at the fore-angles are as wide as at basal half, with the fore-angles somewhat more distinct and angulate (Fig. 3b); in H. walterrossii n. sp. the punctures of the four inner elytral striae are distinctly coarser and wider than the width of striae (about three times wider than striae) (Fig. 4a), in H. nimba they hardly exceed the width of striae (two times wider at most) (Fig. 4b); the long setae extending from the submentum across the concavity in the mentum number four in all the type specimens of $H$. walterrossii n. sp. and number five in $H$. nimba HT.

The key to the species of the alluaudi species group given by Erwin \& Stork (1985) should be changed at couplet 5 as follows:

5 Pronotum with lateral channel rugose and punctulate; elytron with three discal setae in third stria.....

H. katanganus Basilewsky, 1948

- Pronotum with lateral channel smooth; elytron with two discal setae in third stria.. ,...

5 ' Punctures of the four inner elytral striae coarser (three times wider than striae); pronotum less transverse (W/L: 1.51) and its margin at fore angles narrower than at basal half; smaller body size (overall length $<10 \mathrm{~mm}$........H. walterrossii $\mathrm{n}$. sp.

- Punctures of the four inner elytral striae delicate (at most two times as wide as the striae); pronotum more transverse (W/L: 1.55) and its margin at fore angles as wide as at basal half; larger body size (overall length $>10 \mathrm{~mm}$ )

H. nimba Erwin \& Stork, 1985

\section{CONCLUSIONS}

Hiletus walterrossii $\mathrm{n}$. sp. is the seventh Hiletus species so far recorded and the second species of the genus described from Sierra Leone. This new finding is remarkable as $H$. walterrossii $\mathrm{n}$. sp. belongs to the alluaudi group which now includes five species, all rarely found and locally distributed in a few western tropical areas (four species) and in a central-eastern area (one species) of Africa; on the contrary the two species of the versutus group are widely distributed in the western and eastern African tropical areas respectively, also being adequately represented in collections.

The western coastal area from Guinea to Ghana is the richest in Hiletus species and could be regarded as a likely center of speciation of the genus, although the rarity of the records and the widely disjunct distribution of the species in the tribe suggest the need for further investigations in order to properly understand the natural history of this ancient and fascinating taxon.

\section{ACKNOWLEDGMENTS}

The authors are grateful to Walter Rossi for the gift to the authors of the specimens of the new species; to Azadeh Taghavian (MNHNP) for the loan of type material; to Sergio Facchini, Joachim Schmidt and Riccardo Sciaky for the valuable advice and for revising the manuscript; to Danny Shpeley (University of Alberta) for linguistic revision.

\section{REFERENCES}

Assmann T., Drees C., Matern A., Schuldt A., 2011 - Eucamaragnathus desenderi, a new ground beetle species from Africa (Coleoptera, Carabidae). ZooKeys, 100: 37-46.

Aston P., 2015 - First record of the subfamily Hitelinae (Coleoptera, Carabidae) for Hong Kong and China. Hong Kong Entomological Bulletin, 7(1): 4-5.

ERwin T.L., Stork N.E., 1985 - The Hiletini, an ancient and enigmatic tribe of Carabidae with a pantropical distribution (Coleoptera). Systematic Entomology, 10: 405-451.

JEANNEL R., 1937 - Les Hilétides (Coleoptera Adephaga), une lignée africano-brésilienne. Revue Française d'Entomologie, 4: 202-219.

LoRenz W., 2005 - Systematic list of extant ground beetles of the world (Insecta Coleoptera 'Geadephaga': Trachypachidae and Carabidae incl. Paussinae, Cicindelinae, Rhysodinae). Second Edition. Tutzing, 530 pp.

NÈGRE J., 1966 - Remarques sur les Hilétides (Col. Carabiques) avec description de deux espèces nouvelles. Miscellanea Zoologica, 16: 57-62. 